\title{
SENSITIVITY ANALYSIS IN THE REHABILITATION OF HISTORIC TIMBER STRUCTURES ON THE EXAMPLES OF GREEK CATHOLIC CHURCHES IN POLISH SUBCARPATHIA
}

\author{
KATARZYNA SZEPIETOWSKA, IZABELA LUBOWIECKA* \\ Department of Structural Mechanics, Faculty of Civil and Environmental Engineering \\ Gdansk University of Technology \\ Narutowicza 11/12, 80-233 Gdańsk, Poland \\ e-mail: izabela.lubowiecka@pg.edu.pl (*corresponding author) \\ katarzyna.szepietowska@pg.edu.pl
}

Keywords: Historical Structure, Carpentry joints, Structural Analysis, Global sensitivity analysis, Uncertainty quantification

\begin{abstract}
This work concerns structural and sensitivity analysis of carpentry joints used in historic wooden buildings in south-eastern Poland and western Ukraine. These are primarily sacred buildings and the types of joints characteristic for this region are saddle notch and dovetail joints. Thus, in the study the authors focus on these types of corner log joints. Numerical models of the joints are defined and finite element simulations of their statics are carried out. Moreover, a sensitivity analysis is performed in order to describe how the uncertainty of material properties including humidity of some structural members, caused during potential repairs, affect the structural behaviour of the whole connection. This represents the situation when some degraded logs are exchanged into new wood combining old, and often damp, wood with new and dry logs. A non-intrusive probabilistic approach to the sensitivity analysis is applied and regression-based Polynomial Chaos (PC) expansion method is used to propagate uncertainties.
\end{abstract}

\section{INTRODUCTION}

The motivation of the presented research was the survey and the current state of wooden Greek Catholic churches in Polish Subcarpathia (Figure 1), described and analysed in detail in [1]. The susceptibility of wood to rotting and damage reduces the number of those historic buildings, and thus raises the need to preserve this heritage. The construction of this type of structures encourages the authors to deal with their structural elements, like logs and log joints, in terms of their mechanical behaviour. Especially, referring to the situation of repair and replacement of those elements [2].

Nowadays, the necessity of maintenance, renovation and reinforcement of historical structures yields a need for analysis of its mechanical behaviour. Often, the planning for further and more detailed studies is based on basic measurements and structural analysis [3], Finite element method is a common strategy applied to the structural analysis of complex structures [4], [5]. However, one of the problems in the modelling of historic structures are uncertain 
parameters that can come from material [6], geometry [7], [8], and boundary conditions. The properties of wood as a natural material exhibit high variability [9], which depend on age, moisture level [10], decay etc. Moreover, an accurate non-invasive measurement on historic monuments is also challenging [7]. Both types of uncertainties, resulting from the material variability and the structure geometry, can be incorporated into the modelling (see e.g., [11]). The influence of the material properties changes and uncertainties on the structural behaviour can be studied in two ways, by local or global sensitivity analysis.

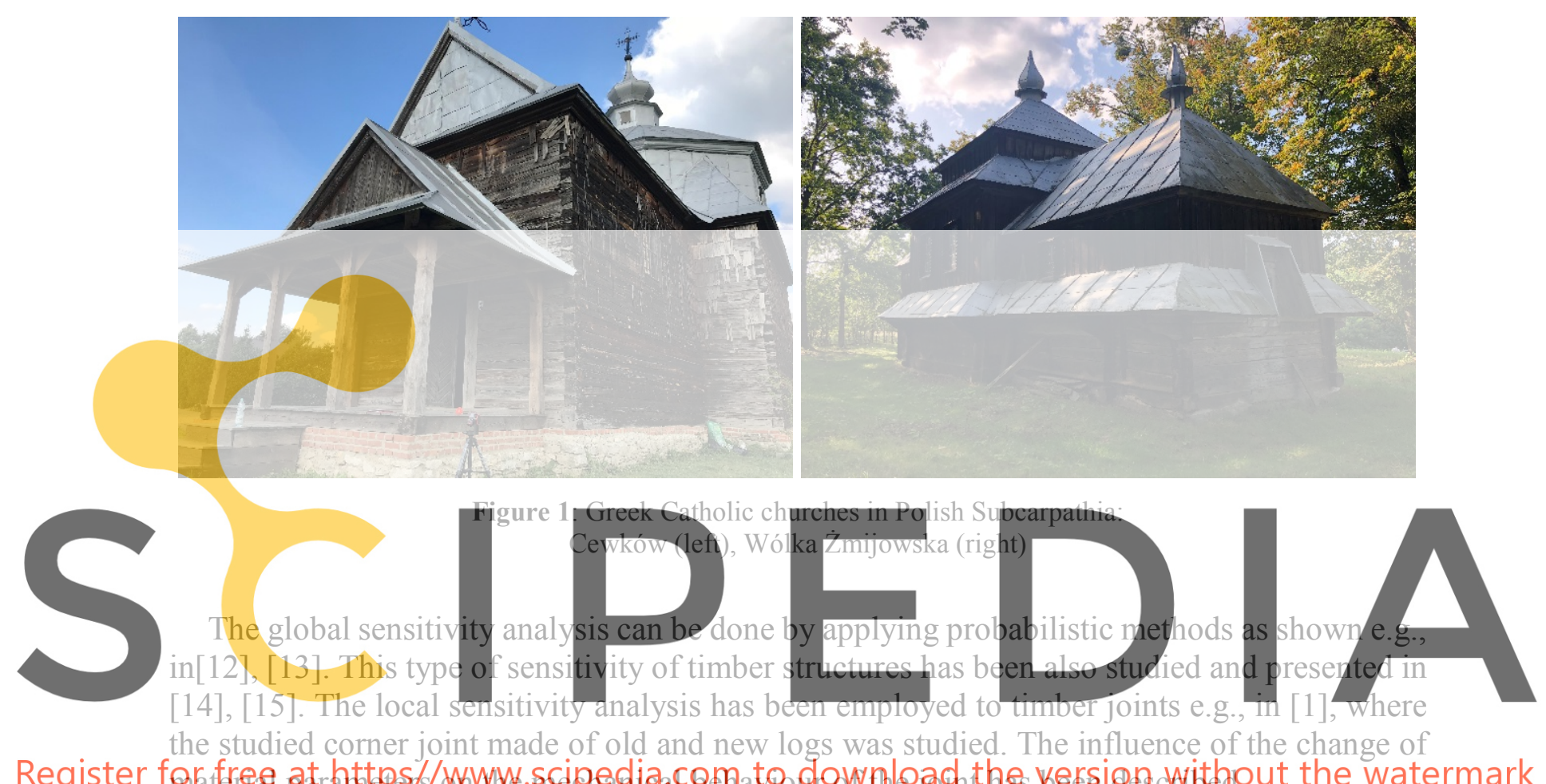

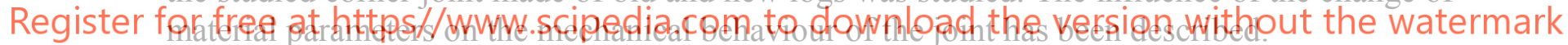

The present study concerns a global sensitivity analysis of corner log joints subjected to

lateral load. There are two types of joints taken into consideration, dovetail and saddle notch (Figure 2) as the most common in this type of structures [16]. A special attention is payed to the change of mechanical behaviour of the joints while exchanging their elements, e.g., when a part of damaged old structure is filled with a new wood. This exchange can be represented by the change of material properties of wood that also involves uncertainties referring to the assessment of those properties in existing structures.

The global sensitivity analysis of corner log joints presented in [6] shown how and which of the two considered material paramaters of wood (elastic modulus and friction coefficient) influence the strutural behaviour of the joints. In the present study, the authors are focused on how an exchange of a structural member influences the behaviour of the joints applying a regression based polynomial chaos expansion method [17] to propagate uncertainties of properties of old wet logs and of a new dry log used for replacement. 


\section{FINITE EMENT MODELLING OF CARPENTRY JOINTS}

\subsection{Geometry and finite element discretisation}

Numerical models of the joints have been defined by means of finite element method. Each of them contain $5 \operatorname{logs}$ (Figure 2) composed in a layout as observed in the churches. Referring to the previous studies, [1], [7], [18], where also some experimental work is addressed, the size of the modelled joints has been scaled 1:2 compared to the real connections. Thus, the $0.7 \mathrm{~m}$ long logs have cross-sections of $75 \times 135 \mathrm{~mm}$. Geometrically nonlinear static analysis has been performed using MSC.Marc commercial software. The joints were discretised by 37864 (dovetails) and 44008 (saddle notch) of 3D, 8-nodes finite elements with 3 translational dof in each node (Figure 2).
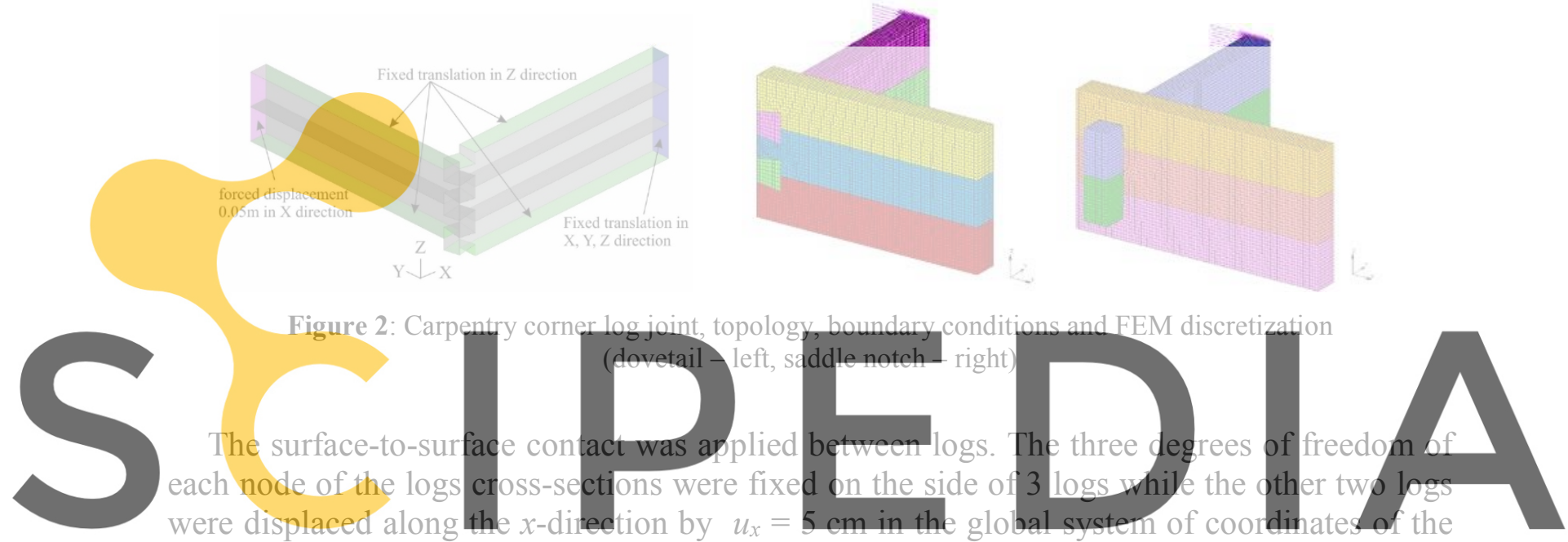

model resulting in a change of the corner angle. The bottom and top surfaces of the joints were

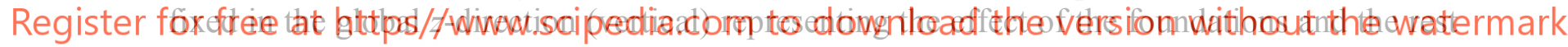
of the wall.

\subsection{Material properties}

In the analysis, wood has been considered as orthotropic elastic material, where $E_{\mathrm{L}}$ is a longitudinal modulus of elasticity (along the direction of the fibres). Following [19], the moduli of the other directions (radial $-\mathrm{R}$ and tangential $-\mathrm{T}$ ) were calculated in relation to $E_{\mathrm{L}}$ according to the formulae $E_{\mathrm{T}} / E_{\mathrm{L}}=0.068, E_{\mathrm{R}} / E_{\mathrm{L}}=0.102, G_{\mathrm{RT}} / E_{\mathrm{L}}=0.05, G_{\mathrm{TL}} / E_{\mathrm{L}}=0.046, G_{\mathrm{LR}} / E_{\mathrm{L}}=$ 0.049 , and appropriate Poisson ratios were determined as $v_{\mathrm{RT}}=0.469, v_{\mathrm{TL}}=0.024, v_{\mathrm{LR}}=0.316$ as described in [15]. It assumed that the joint is made of old wet wood with one middle log replaced by a new dry log.

\section{UNCERTAINTY PROPAGATION AND GLOBAL SENSITIVITY ANALYSIS}

\subsection{Uncertainty propagation}

The applied scheme of uncertainty quantification is presented in Figure 3. The methodology applied to carpentry joints in previous research [15] is also used in this study. In order to 
propagate uncertainties through models defined in commercial FE system, non-intrusive methods can be applied. Such methods do not require FE code modifications and are based on some number of deterministic calculations. Regression-based polynomial chaos (PC) expansion [17] is one of such methods which requires less simulations than widely-used Monte Carlo method. Truncated PC expansion of the model output $Y$ (quantity of interest) is:

$$
Y \approx \sum_{\alpha \in \mathcal{A}} a_{\alpha} \Psi_{\alpha}(\xi)
$$

where $\mathcal{A}$ is a truncation set of $\boldsymbol{\alpha} M$-uplets $\left(\alpha_{1}, \ldots, \alpha_{M}\right) \in \mathbb{N}^{M}$ indicating order of polynomials in a multivariate polynomial basis $\Psi_{\alpha}, a_{\alpha}$ are the coefficients, and $\xi$ are reduced independent variables. Employed polynomials should be orthonormal with respect to a distribution. Therefore Hermite polynomials are used in case of normal (and lognormal) distribution and Legendre polynomials in case of uniform distribution. In regression based approach, the coefficients are found by solving least square problem. The accuracy depends on the number and choice of regression points for which FE calculations are performed. Based on previous experience, a D-optimal solution from random candidate set is chosen here [20]. Such approach have also resulted in sufficient accuracy in case of modelling of carpentry joints in similar problem [15].
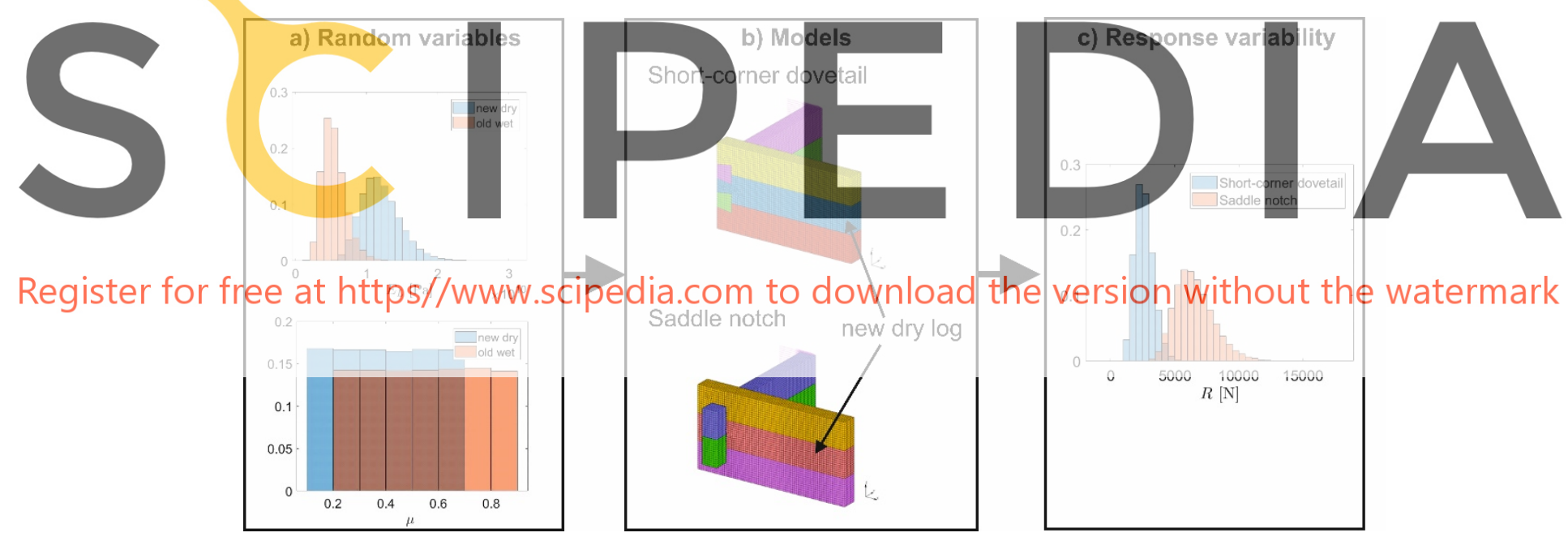

Figure 3: Scheme of uncertainty quantification

\subsection{Global sensitivity analysis}

In order to study the sensitivity of the quantity of interest to the input uncertainty, Sobol' indices are computed [21]. They are measures of global sensitivity and are based on ANalysis Of VAriance (ANOVA) decomposition. Sobol' index $S_{i_{1}, \ldots, i_{s}}$ says how much of the output vriance corresponds to the uncertainty of variables $\xi_{i_{1}}, \ldots, \xi_{i_{s}}$. Thanks to the othonormality of PC basis, the Sobol' indices can be rapidly calculated with the use of PC coefficients 
corresponding to the polynomials depending only on all variables $\xi_{i_{1}}, \ldots, \xi_{i_{s}}[17]$ :

$$
S_{i_{1}, \ldots, i_{s}}=\frac{1}{\sum_{\boldsymbol{\alpha} \in \mathcal{A} \backslash \mathbf{0}} a_{\boldsymbol{\alpha}}^{2}} \sum_{\boldsymbol{\alpha} \in \mathcal{A}_{1, \ldots, i_{s}}} a_{\alpha}^{2},
$$

where:

$$
\mathcal{A}_{i_{1}, \ldots, i_{s}}=\left\{\boldsymbol{\alpha} \in \mathcal{A}: \alpha_{k} \neq 0 \Leftrightarrow k \in\left\{i_{1}, \ldots, i_{s}\right\}\right\}
$$

Total Sobol' index $S_{i}^{T o t}$ is the sum of all indices including variable $i$ and can be calculates as
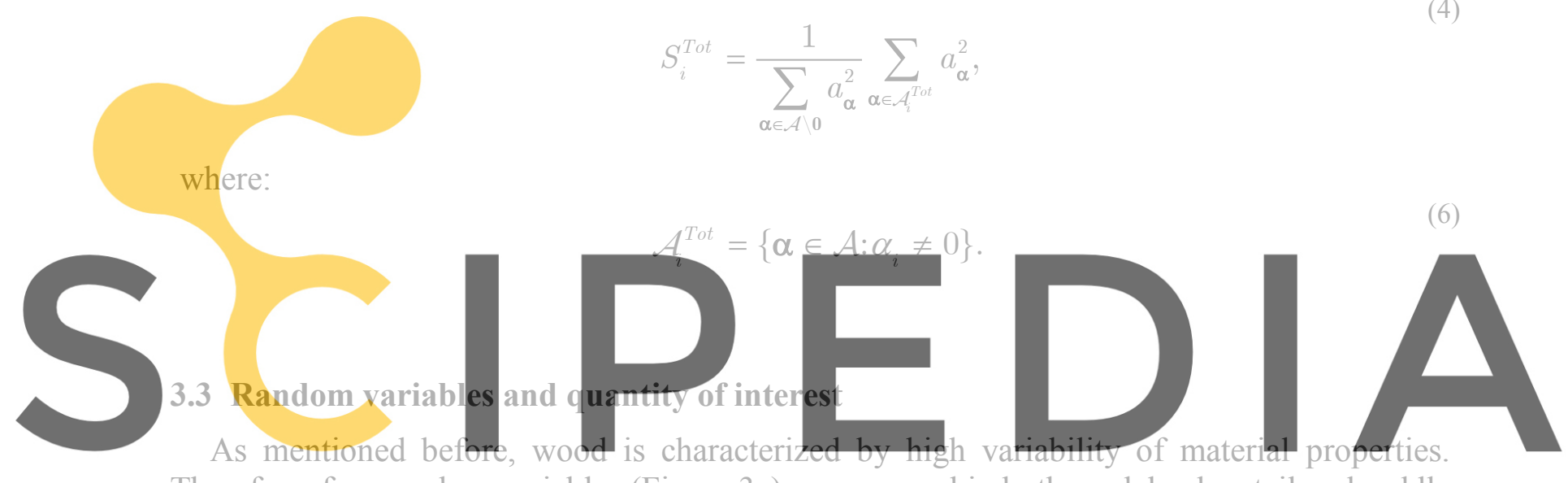

Therefore, four random variables (Figure 3 a) are assumed in both models: dovetail and saddle

Register fort氏kejeiat https//www.scipedia.com to download the version without the watermark

First, the longitudinal Young modulus of the logs is assumed to be a random variable:

1) $E_{L}^{\text {new }} \sim \operatorname{LSN}(23.18,0.23)$ in case of new dry $\log$ (humidity $7-14 \%$ ) with lognormai distribution fitted to experimental results [15];

2) $E_{L}^{\text {old }} \sim \mathcal{L} \mathcal{N}(22.37,0.30)$ in case of old (XIX century) wet logs (humidity $24-40 \%$ ) with lognormal distribution fitted to experimental results [1].

Next, the friction coefficient is assumed to be a random variable with uniform distribution in range based on the data taken from literature [22]-[24] in two variants:

3) $\mu^{\text {new }} \sim \mathcal{U}([0.1,0.7])$ - friction between old wet logs;

4) $\mu^{\text {old }} \sim \mathcal{U}([0.2,0.9])$ - friction between new log and old ones.

The quantity of interest, on which the analysis is focused, is a reaction force $R$ caused by forced lateral displacement of one side of the joint (Figure 2). The study of uncertainty of this value can bring a crucial information for validation of numerical models of carpentry joints when performed with the use of experimental data [18]. 


\section{RESULTS}

The resultant coefficient of variation of reaction force in the models is equal to $28 \%$ for dovetail and $23 \%$ for saddle notch joint. The histogram of the quantity of interest is shown in Figure 3c. Table 1 presents total Sobol' indices calculated using PC expansion. It can be noticed, that their values are relatively similar between the two models. In case of both models, the influence of uncertainty of $E_{L}^{\text {old }}$ (the highest Sobol' index) is highly dominating. The contribution of $E_{L}^{\text {new }}$ to the output variance is very small and the contribution of friction coefficient is negligible when compared to other variables.

Table 1: Total Sobol' indices obtained by PC order 3

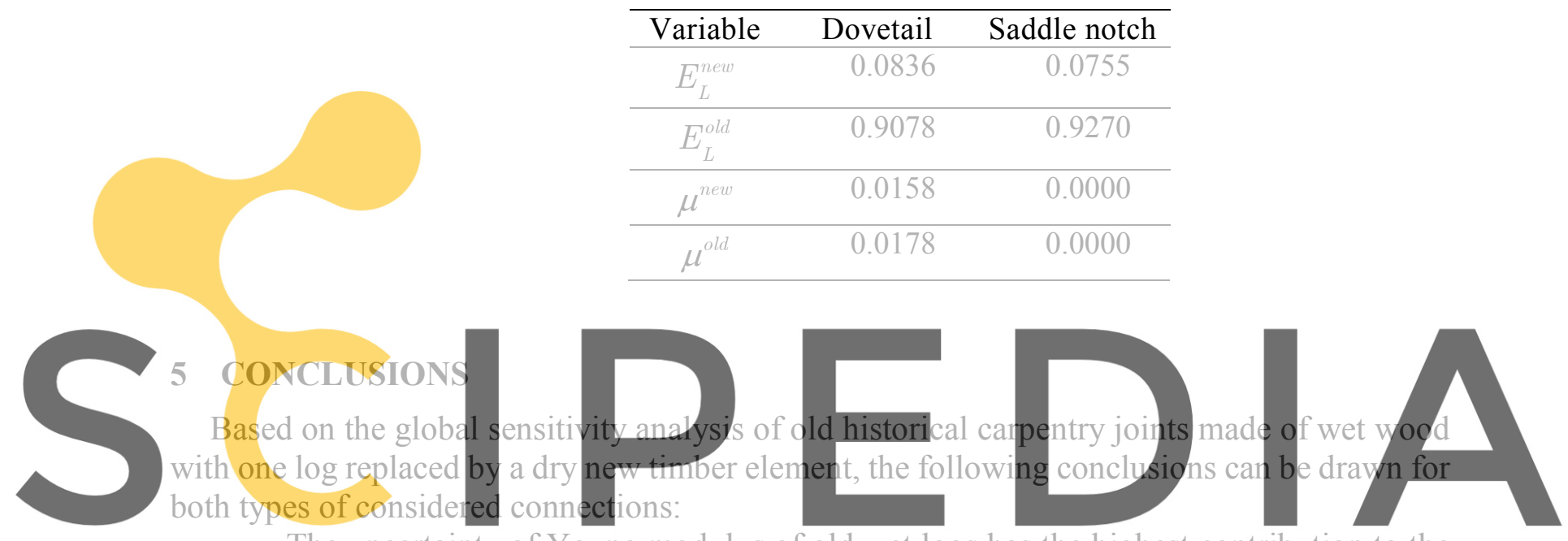

The uncertainty of Young modulus of old wet logs has the highest contribution to the

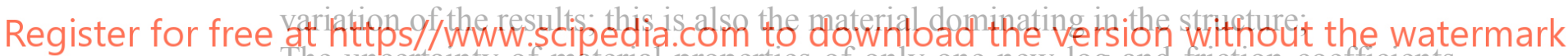
The uncertainty of material properties of only one new log and friction coefficients

have negligible influence on the uncertainty of the outcome.

Therefore, the accurate identification of Young modulus of old logs would most effectively decrease uncertainty of the outcome of the models and consequently should be priority in the future studies. What is more, the considered models could be reduced to a smaller number of random variables, omitting the less important ones, which would reduce the number of simulations required to be performed. The information on contribution of each variable to the uncertainty of the model response can be useful in validation of numerical models by comparison with experiments on carpentry joints. The presented work is part of the research aiming to define credible models which can be used in the rehabilitation process of traditional carpentry joints of Greek Catholic churches in Polish Subcarpathia as well as in other historic timber structures.

Acknowledgements. This work was partially supported by the National Science Centre (Poland) [Grant No. 2015/17/B/ST8/03260]. Calculations were carried out at the Academic Computer Centre in Gdańsk. 


\section{REFERENCES}

[1] I. Lubowiecka, T. Zybała, G. Bukal, M. Krajewski, M. Kujawa, and P. Kłosowski, On the Current State of Dovetail Wall-corner Joints in Wooden Greek Catholic Churches in Polish Subcarpathia with Structural and Sensitivity Analyses, Int. J. Archit. Herit. (2019) 00:1-18.

[2] J. R. Drobiec Łukasz, Pająk Zbigniew, Repair problems of the wooden structure of churches, J. Herit. Conserv. ( 2018) 53:31-44.

[3] H. Cruz et al., Guidelines for On-Site Assessment of Historic Timber Structures Guidelines for On-Site Assessment of Historic Timber Structures, Int. J. Archit. Herit. (2015) 9:277-289.

[4] J. Milch, J. Tippner, V. Sebera, J. Kunecký, M. Kloiber, and M. Navrátil, The numerical assessment of a full-scale historical truss structure reconstructed with use of traditional all-wooden joints, J. Cult. Herit. (2016) 21:759-766.

[5] I. Bergamasco, A. Gesualdo, A. Iannuzzo, and M. Monaco, An integrated approach to the conservation of the roofing structures in the Pompeian Domus, J. Cult. Herit. (2018) 31:141-151.

[6] M. J. Morales-Conde and J. S. Machado, Evaluation of cross-sectional variation of timber bending modulus of elasticity by stress waves, Constr. Build. Mater. (2017) 134:617-625.

[7] J. Hermida, M. Cabaleiro, B. Riveiro, and J. C. Caamaño, Two-dimensional models of

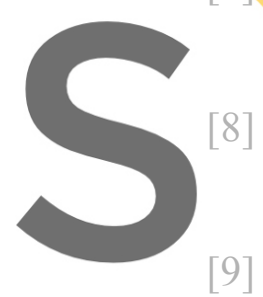
variable inertia from LiDAR data for structural analysis of timber trusses, Constr. Build.
Mater. (2020) 231:117072.
P. B. Lourenço, H. S. Squsa, R. D. Brites, and L. G. Neves, In situ measured cross section
geometry of old timber structures and its influence on structural safety, Mater. Struct.
Constr. (2013) 46:1193-1208.
J. S. Machado, F. Pereira, and T. Quilhó, Assessment of old timber members: Importance of wood species identification and direct tensile test information, Constr. Build. Mater.

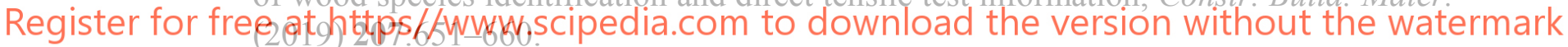

[10] M. Aydin and T. Yilmaz Aydin, Moisture dependent elastic properties of naturally aged biack pine wood, Constr. Build. Mater. (2020) 262:120752.

[11] T. Zybała, K. Szepietowska, G. Bukal, and I. Lubowiecka, Portico farmhouses of the Vistula Delta: architecture, current state and finite element modelling of timber roof truss under material and cross-section uncertainty, Int. J. Archit. Herit. (2021), in press.

[12] J. Köhler, J. D. Sørensen, and M. H. Faber, Probabilistic modeling of timber structures, Struct. Saf. (2007) 29:255-267.

[13] H. S. Sousa and L. C. Neves, Reliability-based design of interventions in deteriorated timber structures, Int. J. Archit. Herit. (2018) 12:507-515.

[14] P. O. Hristov, F. A. DiazDelaO, E. I. Saavedra Flores, C. F. Guzmán, and U. Farooq, Probabilistic sensitivity analysis to understand the influence of micromechanical properties of wood on its macroscopic response, Compos. Struct. (2017) 181:229-239.

[15] P. Klosowski, I. Lubowiecka, A. Pestka, and K. Szepietowska, Historical carpentry corner log joints-Numerical analysis within stochastic framework, Eng. Struct. (2018) 176:64-73.

[16] J. Jasieńko, T. Nowak, and A. Karolak, Historyczne złącza ciesielskie. (Historical 
carpentry joints), J. Herit. Conserv. (2014) 40:58-82.

[17] B. Sudret, Global sensitivity analysis using polynomial chaos expansions, Reliab. Eng. Syst. Saf. (2008) 93:964-979.

[18] P. Kłosowski, A. Pestka, M. Krajewski, and I. Lubowiecka, Experimental and computational study on mechanical behaviour of carpentry corner log joints, Eng. Struct. (2020) 213:110515.

[19] D. W. Green, J. E. Winandy, and D. E. Kretschmann, Wood handbook - Wood as an Engineering Material. Forest Products Laboratory, Madison (1999).

[20] K. Szepietowska, B. Magnain, I. Lubowiecka, and E. Florentin, Sensitivity analysis based on non-intrusive regression-based polynomial chaos expansion for surgical mesh modelling, Struct. Multidiscip. Optim. (2018) 57:1391-1409.

[21] I. M. Sobol', Global sensitivity indices for nonlinear mathematical models and their Monte Carlo estimates, Math. Comput. Simul. (2001) 55:271-280.

[22] P. Grossi, T. Sartori, I. Giongo, and R. Tomasi, Analysis of timber log-house construction system via experimental testing and analytical modelling, Constr. Build. Mater. (2016) 102:1127-1144.

[23] W. M. McKenzie and H. Karpovich, The frictional behaviour of wood, Wood Sci. Technol. (1968) 2:139-152.

[24] M. Xu, L. Li, M. Wang, and B. Luo, Effects of Surface Roughness and Wood Grain on the Friction Coefficient of Wooden Materials for Wood-Wood Frictional Pair, Tribol.
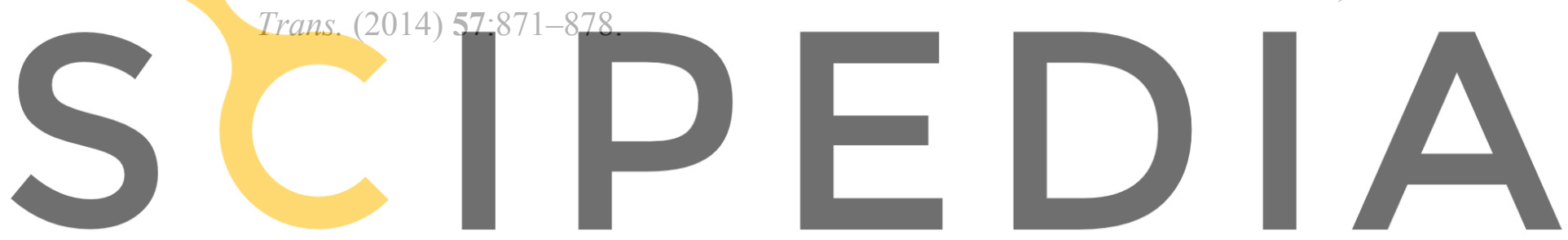

Register for free at https//www.scipedia.com to download the version without the watermark 